\title{
The evaluation and enhancement of quality, environmental protection and seaport safety by using FAHP
}

\author{
Danijela Tadic ${ }^{1}$, Aleksandar Aleksic ${ }^{1}$, Pavle Popovic $^{2}$, Slavko Arsovski ${ }^{1}$, Ana Castelli ${ }^{3}$, Danijela Joksimovic ${ }^{3}$, and \\ Miladin Stefanovic ${ }^{1}$ \\ ${ }^{1}$ Faculty of Engineering, University of Kragujevac, Sestre Janjic 6, 34000 Kragujevac, Serbia \\ ${ }^{2}$ Luka Kotor A.D., Park Slobode 1, 85330 Kotor, Montenegro \\ ${ }^{3}$ Institute of Marine Biology, University of Montenegro, Dobrota bb, P.O. Box 69, 85330 Kotor, Montenegro \\ Correspondence to: Pavle Popovic (pavle.popovic@portofkotor.co.me)
}

Received: 6 April 2016 - Discussion started: 15 April 2016

Revised: 11 January 2017 - Accepted: 24 January 2017 - Published: 23 February 2017

\begin{abstract}
The evaluation and enhancement of business processes in any organization in an uncertain environment presents one of the main requirements of ISO 9000:2008 and has a key effect on competitive advantage and long-term sustainability. The aim of this paper can be defined as the identification and discussion of some of the most important business processes of seaports and the performances of business processes and their key performance indicators (KPIs). The complexity and importance of the treated problem call for analytic methods rather than intuitive decisions. The existing decision variables of the considered problem are described by linguistic expressions which are modelled by triangular fuzzy numbers (TFNs). In this paper, the modified fuzzy extended analytic hierarchy process (FAHP) is proposed. The assessment of the relative importance of each pair of performances and their key performance indicators are stated as a fuzzy group decision-making problem. By using the modified fuzzy extended analytic hierarchy process, the fuzzy rank of business processes of a seaport is obtained. The model is tested through an illustrative example with real-life data, where the obtained data suggest measures which should enhance business strategy and improve key performance indicators. The future improvement is based on benchmark and knowledge sharing.
\end{abstract}

\section{Introduction}

Changes in the business world - above all in the domain of politics, the economy and environment - demand the con- tinuous improvement of business processes that are provided by strategic managers with the goal of increasing business in a seaport. A quality management system (QMS) conforming to ISO 9001:2008 should be considered as an important additional step, in terms of quality, because ISO 9001 also takes into account economic, financial, design and development aspects and introduces a management review for measurement and analysis of a process with the aim of improving performances (Poli et al., 2012). However, this important issue forces every organization to start either with ISO 9000 or total quality management (TQM) as a business strategy (Sedani and Lakhe, 2011). There are various ways in which an enterprise can claim that its QMS meets the requirements of ISO 9001 (Ali, 2014).

Lately, economics, geography and operations research including risk management (John et al., 2014) have dominated seaport research. The impact of multidisciplinarity and interdisciplinarity has significantly increased, and management studies have also substantially increased since the 2000s (Woo et al., 2011).

Seaport operations may be described with many uncertainties, so lately there have been many papers that deal with risk management models (John et al., 2014) and metrics, proposed and numerically implemented to assess the overall performance of large systems, during natural disasters and their recovery and resilience (Shafieezadeh and Burden, 2014). This is due to the fact that much of the available data associated with port operations require a flexible but robust approach to the handling and updating of existing information with new data. As risk management activities are ori- 
ented toward safety, port safety evaluation (Pak et al., 2015) is the first step in overall safety enhancement. After quality management certification, the determining of performances of business processes is based on predefined critical success factors (Oakland, 2004).

Motivation for this research comes from the fact that there are no research papers that treat seaports in the context of the process approach - an assessment of business processes' performances and their improvement which may be obtained by the application of different methods. These methods are developed on a different mathematical and logical framework. According to results of good practice, it is known that it is almost impossible to enhance all business processes at the same time, keeping in mind overall complexity and definite resources (costs, time, human resources, etc.). Enhancement activities are based on the already defined priority of business processes. Business processes may be described by different performances. Different preferences of business processes may vary depending on the needs of the seaport's business strategy, international standards related to seaport services and change of the environment, etc. According to the results of seaport good practice, the key performance indicators (KPIs) of business processes may be defined. It may be assumed that the defined performances and their KPIs do not have the same relative importance. In compliance with this assumption, it can be said that priorities of business processes can be stated as a multi-criteria optimization problem.

The wider objective of this research may be interpreted as an integration of the process approach, the management of business processes and multi-criteria optimization methods. The mentioned integration includes (a) the presentation of a seaport as a network of unrelated business processes so the overall success of the business processes may be assessed on the level of predefined criteria; (b) the assessment of business processes by fuzzy analytic hierarchy process (FAHP); (c) the definition of management initiatives which should lead to the improvement of business success. The order of taking management initiatives is based on the obtained rank of business processes.

This paper continues to investigate beyond the existing seaport literature and intends to consider all the significant performances, which have not had much attention in the management of business processes. The main contribution of the proposed model is that by its application, the fuzzy rank of business processes and the degree of belief that one business process is better than another with respect to each business' performance can be obtained.

As the environment changes rapidly or becomes uncertain, the values of some performances and their relative importance become difficult or impossible to quantify. All existing uncertainties can be adequately described by linguistic expressions which are modelled by applying the fuzzy sets theory (Klir and Folger, 1988; Zimmermann, 2001). The fuzzy sets theory resembles human reasoning in its use of approximate information and uncertainty to generate decisions. It may be suggested that the fuzzy approach to treating uncertainties in real-wold applications has numerous advantages when compared to other approaches such as applying the probability theory and the rough set theory. The appropriate technique for determining the rank of business processes with respect to all identified performances in a seaport is FAHP. It is assumed that FAHP is closer to human thinking that the relative importance of KPIs and performances of business processes are assigned according to a pairwise comparison matrix (Saaty, 2008). The issue of evaluation of the relative importance of performances and their KPIs may be based on the FAHP framework (Chan and Kumar, 2007; Kaya and Kahraman, 2011; Tadic et al., 2015; Hsu, 2012; Kuo et al., 1999). It is assumed that all experts do not have equal importance, so in this paper the aggregation of the individual opinions of experts is performed by using fuzzy ordered weighted averaging (FOWA) (Merigo and Casanovas, 2008) (by comparison to Aleksic et al., 2013; Tadic et al., 2015).

The main difference between FAHP and the other methods in the literature is its modelling of a decision problem in a holistic manner. This method offers a number of benefits because (1) the other multi-criteria methods experience difficulty in capturing uncertain and imprecise judgments of experts and (2) FAHP is an efficient tool for handling the fuzziness of the data involved in deciding the preferences or assessment of different decision variables. In this paper, a new approach for handling pairwise comparison based on trapezoidal fuzzy numbers (Wu et al., 2004) is used.

In the literature, there are many developed approaches for handling FAHP. The use of the developed approach (Chang, 1996) does not involve cumbersome mathematical operations, and it has the ability to capture the vagueness of the human thinking style. Wang et al. (2008) have shown that the extent analysis method cannot estimate the true weights from a fuzzy comparison matrix and has led to quite a number of misapplications. There are many differences between traditional FAHP (Chang, 1996) and the FAHP which is proposed in Wu et al. (2004). Firstly, fuzzy numbers can extend the range of a crisp comparison matrix of the AHP method. Secondly, in the proposed method, the weights of the criteria and preferences of an alternative under each criterion are derived from the fuzzy preference rations; thus, the developed approach allows for a more reasonable description of the decision-making process and reflects the thinking style of a human.

\section{Analysis of performances, key performances indicators and business processes in a seaport}

The product of seaports belongs to a generic product categories called a service (ISO 2000:2007). Respecting ISO 20000-1:2010 (point 2.15) and the above definition of the service term, seaports can be denoted as service 
providers. The management of services to meet business requirements (ISO 20000-1:2010) can be maintained, above all, by the application of a continual improvement principle of business processes. The ranking of business processes is stated as a problem which has a hierarchy of three levels. The performances, KPIs of performances and the business processes will be further discussed. The considered performances of business processes are quality, environmental protection and seaport safety. These performances can be decomposed into various other KPIs, which are described in the following subsections.

\subsection{Quality}

Quality is defined as the degree to which a set of inherent characteristics fulfil requirements (ISO 9000:2005), so fuzzy sets may be used when it needs to be assessed (Yaqiong et al., 2011). This performance of a business process has a high impact on customers, income and indirectly on the long-term sustainability of the seaport. The KPIs affecting this performance can be determined through the use of literature data and as a result of good practice. KPIs of the quality (Tadic et al., 2013) of seaport services are derived from ISO 9001:2008 and Resolution 10011 and are described as follows.

\subsubsection{Quality of the seaport services (Q1)}

A seaport usually defines this KPI through the satisfaction and loyalty (ISO 10002:2014; ISO 10003:2007) of customers. It is supported by the quality of the internal customeroriented activities of the seaport and customers' perception of these activities.

\subsubsection{Average number of customers (Q2)}

This KPI is very important for overall profit, the local community and company image. The impact on the local community is important since customers satisfy their needs in a seaport by using the infrastructure around it (hotel services, banking services, shops, etc.).

\subsubsection{Average number of vessels in the queue $(\mathrm{Q3})$}

As a seaport is customer oriented, this number should be as low as possible so the satisfaction of vessel owners and passengers will be increased. Additionally, this performance is important for different organizational units of the seaport such as repair services or services for loading and unloading vessels. This should be assessed in communication with the different services in the seaport that define approach positions and anchoring places of vessels.

\subsubsection{Pilotage and operation of the vessel $(Q 4)$}

This performance is important from the perspective of vessel owners, customers and seaport management. All of them always require the minimum time needed for placing vessels in the limited seaport infrastructure. This should lead to overall cost minimization.

\subsection{Environmental protection}

In seaports worldwide, many accidents may occur, leading to the pollution of the environment and biodiversity change. This is further linked to the decrease of business effectiveness in a seaport and, in the worst case scenario, it can lead to total stoppage of provision of seaport services. It is important that maritime transport operates in a safe, secure and environmentally friendly way, so the EU has introduced legislation under Port State Control Directive 95/21. Besides this, ISO 14001:2004 sets out the criteria for an environmental management system (EMS) so that, in compliance with its demands, KPIs that describe environmental protection can be measured in terms of the following.

\subsubsection{Quality of air (E1)}

The level of air quality is important from the perspective of public health and change of biodiversity. It is determined and should be assessed by the level of smoke, dust and harmful gasses present. According to the evidence data, around $95.75 \% \mathrm{CO}_{2}, 22 \%$ nitrogen oxides and $0.6 \%$ sulfur oxides are emitted into the air. All of these could lead to greenhouse effects and damage of the ozone layer.

\subsubsection{Water quality (E2)}

This KPI is related to the protection of sea biodiversity, tourists and the local community. The level of water quality depends on the presence of microbiological, mechanical and chemical substances which are discharged by vessels entering the seaport.

\subsubsection{Noise (E3)}

This is significant from the perspective of customers. The other interested party is seaport management since noise represents a source of pollution. The increase in noise level may lead to change in biodiversity and to the minimization of profits since it reduces the satisfaction of customers and other stakeholders.

\subsubsection{Hazardous substances (E4)}

Hazardous substances may be generated in the majority of technical processes in a seaport and they potentially represent the most dangerous pollution source for the environment. The management of hazardous substances is a very im- 


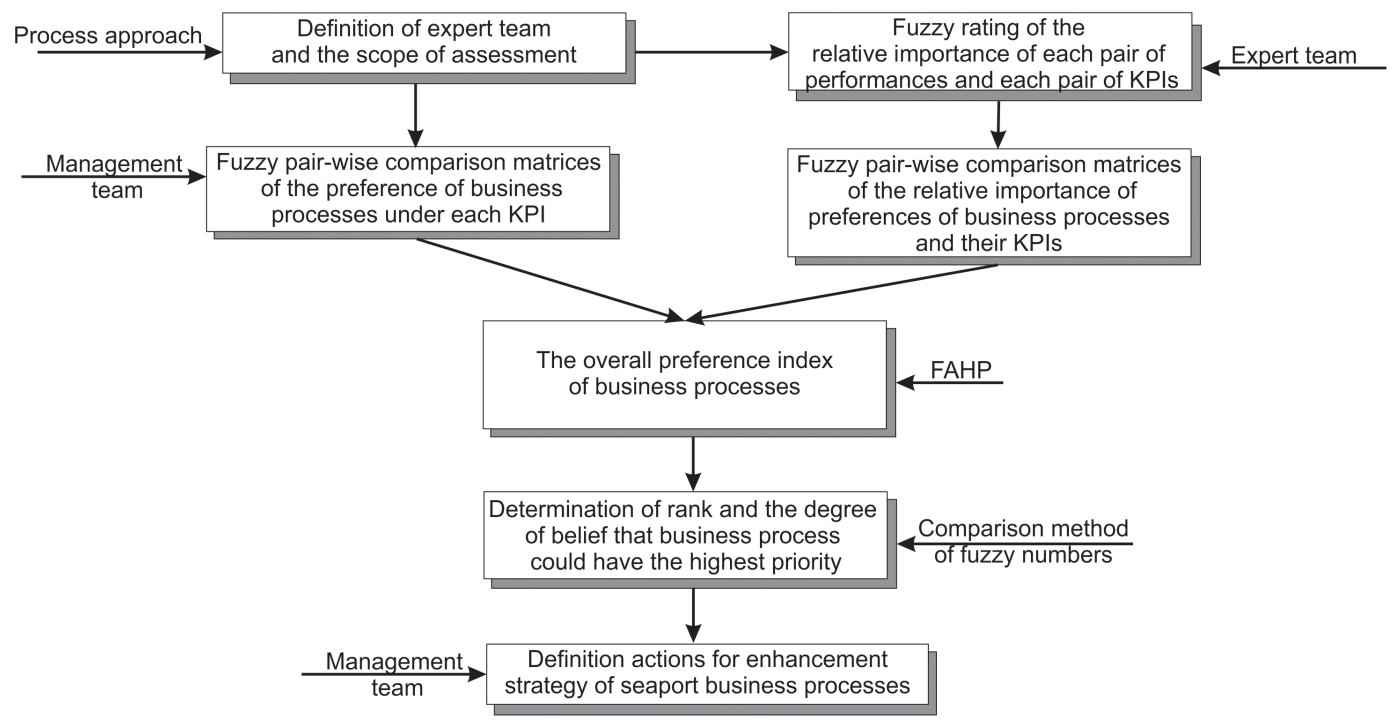

Figure 1. The evaluation procedure of seaport business processes by FAHP.

portant task for a seaport when keeping biodiversity, public health and long-term sustainability in mind.

\subsection{Seaport safety}

This significant performance has to meet legislative demands and has a serious impact on seaport competitiveness. Different accidents could occur in ports, causing extensive loss of life, damage to vessels and cargo, serious water pollution and changes in biodiversity. The KPIs of seaport safety may be defined based on the literature (Pak et al., 2015; Trbojevic and Carr, 2000). Based on the literature review (Pak et al., 2015) and evidence data of Montenegro seaports, the following KPIs are identified as the most significant.

\subsubsection{Vessel safety (S1)}

This KPI is related to the number of accidents caused, for example, by the collision of vessels in the port and docks, unmooring from the dock and capsizing of small boats. This KPI may be assessed by taking into account (Trbojevic and Carr, 2000) size, type, age, crew, maneuverability, pilotage requirements and escorting requirements of the vessel.

\subsubsection{Traffic volume (S2)}

A traffic-related factor may be seen as the "volume of traffic inside a port" (Pak et al., 2015). While assessing this KPI, a comprehensive database of port accidents may be used.

\subsubsection{Weather, sea, and channel conditions (S3)}

This KPI deals with (1) weather conditions, such as wind speed, sea state and visibility (Balmat et al., 2009) and
(2) channel conditions including the perspectives of depth, complexity and width (Pak et al., 2015).

\subsubsection{Other safety factors (S4)}

Many factors impact the safety of the port and thus they may be addressed as one joint KPI and taken into account. These factors may include, for example, fire safety, in-port communication, terrorist attacks and natural disasters.

\section{The model for evaluation of seaport business processes}

The proposed evaluation procedure using FAHP is presented in Fig. 1.

The evaluation procedure should be delivered by the expert team, which is comprised of the owner, main manager, local government and the operational management of the seaport. Formally, this expert team is presented by a set of indices $\{1, \ldots, e, \ldots, E\}$. The index for an expert is denoted as $e$, and $E$ is the total number of experts. The members of the expert team have different influences in the considered decision-making process. The importance of experts, $w_{\mathrm{e}}, e=1, \ldots, E$, should be determined with respect to the results of good practice.

The identified performances can be presented by the set of indices $\{1, \ldots, k, \ldots, K\}$. The index for a performance is denoted as $k, k=1, \ldots, K$ and $K$ is the total number of identified performances. Each performance $k, k=1, \ldots, K$ is decomposed into KPIs. Generally, KPIs under performance $k, k=1, \ldots, K$ are presented by the set of indices $\left\{1, \ldots, j, \ldots, J_{k}\right\}$.

Experts and operational managers use the predefined linguistic expressions, which are modelled by triangular fuzzy 
numbers (TFNs). The shape of the membership functions can be obtained based on one's experience, the subjective belief of decision makers and their knowledge. Jointly used shapes of triangular function offer a good compromise between descriptive power and computational simplicity.

The total number of KPIs under performance $k$, $k=1, \ldots, K$ is denoted as $J_{k} ; j$ is the index for KPI $j$, $j=1, \ldots, J_{k}$.

The fuzzy rating of the relative importance of each pair of performances and their KPIs is described by each expert and presented by TFN $\widetilde{W}_{k k}^{\mathrm{e}^{\prime}}=\left(l_{k k}^{\mathrm{e}^{\prime}}, m_{k k}^{\mathrm{e}^{\prime}} u_{k k}^{\mathrm{e}^{\prime}}\right), k=1, \ldots, K$ and $\widetilde{V}_{j j}^{\mathrm{e}^{\prime}}=\left(l_{j j}^{\mathrm{e}^{\prime}}, m_{j j}^{\mathrm{e}^{\prime}} u_{j j}^{\mathrm{e}^{\prime}}\right), j=1, \ldots, J_{k}$.

The aggregation of individual opinions into a group consensus is calculated by the performed fuzzy ordered weighted averaging operator (Merigo and Casanovas, 2008). The aggregated value of the considered variables is

$\widetilde{W}_{k k}^{\prime}=\left(l_{k k}^{\prime}, m_{k k}^{\prime} u_{k k}^{\prime}\right)=\sum_{e=1}^{\mathrm{E}} w_{\mathrm{e}} \widetilde{\dot{W}}_{k k}^{\mathrm{e}^{\prime}}, k=1, \ldots, K ; e=1, \ldots, E$.

Similarly, the aggregated value of the relative importance of each pair of KPIs under the identified performance is determined.

Fuzzy pairwise comparison matrices of the relative importance of performance and the relative importance under performance and preference of business processes of each KPI are stated. It is necessary to determine the coefficient of consistency to reflect the consistency of the decision makers' judgement during the evaluation phase by using the eigenvector method (Saaty, 2008). The eigenvector method represents a natural measure for inconsistency and it is used extensively in the literature and in this paper. It is worth mentioning that all relevant consistency indices (C.I.'s) should be equal to or below the threshold of 0.1 . The weights vector of performances, weights vector of KPIs under each performance and the preference vector of business processes with respect to each KPI are determined by FAHP, which is developed in Wu et al. (2004).

The developed procedure is illustrated on the example of determination of the performances' weights vector in compliance with Eqs. (2) and (3):

$$
\begin{array}{r}
\alpha_{k}=\left[\prod_{k=1}^{K} l_{k k^{\prime}}\right]^{1 / K}, \beta_{k}=\left[\prod_{k=1}^{K} m_{k k^{\prime}}\right]^{1 / K}, \\
\quad \text { and } \gamma_{k}=\left[\prod_{k=1}^{K} u_{k k^{\prime}}\right]^{1 / K}, k=1, \ldots, K
\end{array}
$$

and

$\alpha=\sum_{k=1}^{K} \alpha_{k}, \beta=\sum_{k=1}^{K} \beta_{k}$ and $\gamma_{k}=\sum_{k=1}^{K} \chi_{k}, k=1, \ldots, K$

The weight of performance, $k=1, \ldots, K$, is calculated as

$\widetilde{w}_{k}=\left(\alpha_{k} \gamma^{-1}, \beta_{k} \beta^{-1}, \gamma_{k} \alpha^{-1}\right)=\left(l_{k}, m_{k}, u_{k}\right)$.
Table 1. Identified business processes in the seaport.

\begin{tabular}{ll}
\hline $\begin{array}{l}\text { Running } \\
\text { index }\end{array}$ & Title of the business process \\
\hline$p=1$ & Planning and service monitoring \\
$p=2$ & Technology management of service providing \\
$p=3$ & Maintenance of infrastructure \\
$p=4$ & Management of environmental health and safety \\
$p=5$ & Activities in the seaport \\
\hline
\end{tabular}

The weight of KPI $j, \widetilde{v}_{j}^{k}=\left(l_{j}^{k}, m_{j}^{k}, u_{j}^{k}\right), j=1, \ldots, J_{k}$, $k=1, \ldots, K$ and the preference of business process $i$ $p \widetilde{k}_{i j}=\left(l_{i}^{j}, m_{i}^{j}, u_{i}^{j}\right), i=1, \ldots, I$ are calculated in a similar way to Eqs. (2) and (3).

The reference model of an organization (in this case a seaport) may be seen as a general model which can be used to gain other forms of models (Spiegel and Caulliraux, 2012). In compliance with this, an organization may be viewed as a network of interrelated processes that are focused towards achieving organizational goals (Oakland, 2004). The defining of seaport business processes is based on the process approach (ISO 9000:2008) and the assessment of seaport operational management (quality manager, environmental manager and security manager). The identified business processes are presented by the set of indices $\{1, \ldots, i, \ldots$, $I$ \}. The total number of treated business processes is $I$ and $i$, $i=1, \ldots, I$ is the index of the business process. The assessment of the relative preference value of each pair of business processes is achieved by group consensus.

The ranking of business processes is performed according to the overall index of preference. The preference index of business process $i, i=1, \ldots, I$ under performance $k$ can be calculated as

$\widetilde{a}_{i}^{k}=\sum_{j=1}^{J_{k}} \widetilde{v}_{j}^{k} \cdot \widetilde{p}_{i j}^{k}, i=1, \ldots, I ; j=1, \ldots, J_{k} ; k=1, \ldots, K$.

The overall preference index of each business process is described by a TFN. The overall preference index of business process $i, i=1, \ldots, I$ can be calculated as

$\widetilde{a}_{i}=\sum_{k=1}^{K} \widetilde{w}_{k} \cdot \widetilde{a}_{i}^{k} i=1, \ldots, I ; j=1, \ldots, J_{k} ; k=1, \ldots, K$.

The rank of business processes corresponds to the rank of TFNs which are described by the overall indices' preferences.

The ranking of the TFNs $\widetilde{p}_{i}, i=1, \ldots, I$ and the calculation of the degree of belief that other business processes can be better than the business process placed first in the rank are based on the method for comparison of fuzzy numbers (Bass and Kwakernaak, 1977; Dubois and Prade, 1979). 
Table 2. Notation.

\begin{tabular}{lccc}
\hline & $\begin{array}{c}\text { Running } \\
\text { index }\end{array}$ & $\begin{array}{c}\text { Set } \\
\text { size } \\
\text { symbol }\end{array}$ & $\begin{array}{c}\text { Set } \\
\text { size }\end{array}$ \\
\hline Experts & $\mathrm{e}$ & $E$ & 4 \\
Performances & $\mathrm{k}$ & $K$ & 3 \\
KPI of $k$ th performance & $\mathrm{J}$ & $J_{k}$ & 4 \\
Business process & $\mathrm{I}$ & $I$ & 5 \\
\hline
\end{tabular}

\section{Application of FAHP in business processes' ranking}

The proposed model was tested in the Kotor seaport, located in a region protected under national legislation. In recent years, the seaport has been certified with ISO 9001:2008 and ISO 14001:2004. This seaport is a relatively small port so this fact is taken into account during the definition of the reference model of the organization.

In literature concerning business process management, processes of seaport services represent the processes of realization (Arsovski, 2013). The number and type of business processes in a seaport is defined with respect to the American Productivity and Quality Center (APQC) Process Classification Framework (PCF) and process owner's opinion (Table 1). A short description of the selected business processes in ports is further discussed.

\subsection{Selected business processes in ports}

\subsubsection{Planning and service monitoring $(p=1)$}

This process covers a set of activities to be implemented under the common goals of the process (responsibility for each activity, resources, timelines and desired outputs from each activity in terms of the characteristics of services and processes). This corresponds to the "Plan for and align supply chain resources" process which is defined in the APQC specification.

\subsubsection{Technology management of service providing $(p=2)$}

This process covers standard procedures for vessel access to the port, pilotage, maintenance, port transportation, disembarking and cleaning, among others.

\subsubsection{Maintenance of infrastructure $(p=3)$}

This process covers maintenance procedures of docks, cranes, warehouses and roads, as well as other transport manipulating systems. This corresponds to the "Manage logistics and warehousing" process (defined in APQC).
Table 3. Specific weights of expert team.

\begin{tabular}{lc}
\hline Experts & $\begin{array}{c}\text { Specific weight } \\
\text { of the expert }\end{array}$ \\
\hline Seaport owner & 0.4 \\
Main manager & 0.3 \\
Local government expert & 0.2 \\
The representative of operational & 0.1 \\
management of the seaport & \\
\hline
\end{tabular}

\subsubsection{Management of environmental health and safety $(p=4)$}

This process is defined in compliance with the APQC specification and is important from the perspective of seaport sustainability. The effectiveness of this business process is important for the management of the port and the local and state administration.

\subsubsection{Activities in the seaport $(p=5)$}

This is a complex business process where many different activities are defined and realized according to APQC and literature data (Medison, 2005). These activities are material purchase, service delivery to seaport customers, marketing and service sale, management of customer demands, management of information technology and knowledge, management of financial resources and management of external relations.

\subsection{Business processes' ranking on real-life data}

The notation used is provided in Table 2.

Based on the internal policy of the treated seaport, the expert team is adjoined with different specific weights (Table 3).

The elements of the constructed fuzzy pairwise matrices are defuzzified and the consistency of the fuzzy pairwise matrices is determined. This is determined by comparison with Torfi et al. (2010).

The weight of quality performance $(k=1)$ is then calculated in compliance with Eqs. (2) and (4):

$$
\begin{aligned}
\widetilde{w}_{1} & =\left(0.89 \cdot 3.95^{-1}, 1.25 \cdot 3.22^{-1}, 1.53 \cdot 2.65^{-1}\right) \\
& =0.24,0.39,0.58) .
\end{aligned}
$$

Similarly, the weights of the rest of the performances are calculated:

$\widetilde{w}_{2}=(0.12,0.17,0.25)$ and $\widetilde{w}_{3}=(0.30,0.44,0.66)$.

The weights of sub-criteria under quality performance are

$\widetilde{v}_{1}^{1}=(0.19,0.28,0.38), \widetilde{v}_{2}^{1}=(0.19,0.29,0.41)$,

$\widetilde{v}_{3}^{1}=(0.09,0.14,0.25)$ and $\widetilde{v}_{4}^{1}=(0.21,0.28,0.41)$. 
The weights of KPIs under environmental protection performance are

$\widetilde{v}_{1}^{2}=(0.09,0.14,0.25), \widetilde{v}_{2}^{2}=(0.21,0.39,0.59)$,

$\widetilde{v}_{3}^{2}=(0.11,0.20,0.36)$ and $\widetilde{v}_{4}^{2}=(0.18,0.27,0.48)$.

The weights of KPIs under safety performance are

$\widetilde{v}_{1}^{3}=(0.26,0.38,0.52), \widetilde{v}_{2}^{3}=(0.29,0.41,0.58)$,

$\widetilde{v}_{3}^{3}=(0.09,0.14,0.22)$ and $\widetilde{v}_{4}^{3}=(0.06,0.07,0.11)$.

The preference of KPIs under each considered performance is presented as follows.

\subsubsection{Quality performance}

(Q1) Quality of the seaport services

$\tilde{p}_{11}^{1}=(0.12,0.22,0.41), \tilde{p}_{21}^{1}=(0.11,0.19,0.38)$,

$\tilde{p}_{31}^{1}=(0.05,0.07,0.14), \tilde{p}_{41}^{1}=(0.05,0.08,0.14)$

and $\tilde{p}_{51}^{1}=(0.25,0.43,0.68)$.

(Q2) Average number of customers

$\tilde{p}_{12}^{1}=(0.28,0.43,0.62), \tilde{p}_{22}^{1}=(0.14,0.19,0.29)$,

$\tilde{p}_{32}^{1}=(0.04,0.06,0.09), \tilde{p}_{42}^{1}=(0.07,0.10,0.16)$

and $\tilde{p}_{52}^{1}=(0.14,0.23,0.34)$.

(Q3) Average number of vessels in the queue

$\tilde{p}_{13}^{1}=(0.25,0.44,0.72), \tilde{p}_{23}^{1}=(0.1,0.17,0.3)$,

$\tilde{p}_{33}^{1}=(0.08,0.13,0.26), \tilde{p}_{43}^{1}=(0.06,0.09,0.2)$

and $\tilde{p}_{53}^{1}=(0.12,0.17,0.27)$.

(Q4) Pilotage and operation of the vessel

$\tilde{p}_{14}^{1}=(0.15,0.29,0.58), \tilde{p}_{24}^{1}=(0.14,0.28,0.54)$,

$\tilde{p}_{34}^{1}=(0.09,0.21,0.34), \tilde{p}_{44}^{1}=(0.06,0.1,0.14)$

and $\tilde{p}_{54}^{1}=(0.07,0.13,0.26)$.

\subsubsection{Environmental protection}

(E1) Quality of air

$\widetilde{p}_{11}^{2}=(0.11,0.18,0.32), \widetilde{p}_{21}^{2}=(0.17,0.27,0.40)$,

$\widetilde{p}_{31}^{2}=(0.15,0.25,0.44), \widetilde{p}_{41}^{2}=(0.07,0.12,0.23)$

and $\widetilde{p}_{51}^{2}=(0.10,0.17,0.25)$.
(E2) Water quality and (E3) noise

$\widetilde{p}_{12}^{2}=\widetilde{p}_{13}^{2}=(0.09,0.13,0.24)$,

$\tilde{p}_{22}^{2}=\widetilde{p}_{23}^{2}=(0.22,0.34,0.59)$,

$\tilde{p}_{32}^{2}=\widetilde{p}_{33}^{2}=(0.19,0.34,0.51)$,

$\widetilde{p}_{42}^{2}=\widetilde{p}_{43}^{2}=(0.05,0.08,0.14)$

and $\widetilde{p}_{52}^{2}=\widetilde{p}_{53}^{2}=(0.06,0.11,0.18)$.

(E4) Hazardous substances

$\widetilde{p}_{14}^{2}=(0.15,0.26,0.4), \widetilde{p}_{24}^{2}=(0.18,0.33,0.53)$,

$\widetilde{p}_{34}^{2}=(0.14,0.23,0.43), \widetilde{p}_{44}^{2}=(0.05,0.07,0.12)$

and $\tilde{p}_{54}^{2}=(0.07,0.11,0.22)$.

\subsubsection{Seaport safety}

(S1) Vessel safety

$\widetilde{p}_{11}^{3}=(0.12,0.19,0.35), \widetilde{p}_{21}^{3}=(0.14,0.31,0.54)$,

$\widetilde{p}_{31}^{3}=(0.11,0.19,0.43), \widetilde{p}_{41}^{3}=(0.06,0.12,0.23)$

and $\widetilde{p}_{51}^{3}=(0.09,0.19,0.38)$.

(S2) Traffic volume

$\widetilde{p}_{12}^{3}=(0.14,0.18,0.36), \widetilde{p}_{22}^{3}=(0.2,0.37,0.56)$,

$\widetilde{p}_{32}^{3}=(0.12,0.21,0.35), \widetilde{p}_{42}^{3}=(0.06,0.11,0.16)$

and $\tilde{p}_{52}^{3}=(0.08,0.13,0.24)$.

(S3) Weather, sea, and channel conditions

$\widetilde{p}_{13}^{3}=(0.06,0.09,0.16), \widetilde{p}_{23}^{3}=(0.09,0.14,0.24)$,

$\widetilde{p}_{33}^{3}=(0.06,0.11,0.18), \widetilde{p}_{43}^{3}=(0.09,0.16,0.30)$

and $\tilde{p}_{53}^{3}=(0.31,0.49,0.74)$.

(S4) Other safety factors

$\widetilde{p}_{14}^{3}=(0.07,0.12,0.19), \widetilde{p}_{24}^{3}=(0.06,0.12,0.20)$,

$\widetilde{p}_{34}^{3}=(0.06,0.11,0.25), \widetilde{p}_{44}^{3}=(0.13,0.23,0.45)$

and $\widetilde{p}_{54}^{3}=(0.24,0.44,0.71)$.

Preference indices of business processes under each identified criterion were calculated by using this procedure. The rank of business processes under the evaluation criteria was determined.

The calculated preference indices of the treated business processes and their rank under the identified evaluation criteria are presented in Tables 4-6. 
Table 4. Preference indices of business processes and their rank under quality performance.

\begin{tabular}{lrrr}
\hline $\begin{array}{l}\text { Process } \\
\text { no. }\end{array}$ & Preference index & Rank & $\begin{array}{r}\text { Degree of } \\
\text { belief that } \\
\text { business } \\
\text { process can } \\
\text { be the best }\end{array}$ \\
\hline$p=1$ & $(0.13,0.329,0.828)$ & 1 & 1 \\
$p=2$ & $(0.086,0.211,0.559)$ & 3 & 0.784 \\
$p=3$ & $(0.085,0.114,0.294)$ & 4 & 0.432 \\
$p=4$ & $(0.041,0.092,0.226)$ & 5 & 0.288 \\
$p=5$ & $(0.097,0.247,0.379)$ & 2 & 0.752 \\
\hline
\end{tabular}

Table 5. Preference indices of business processes and their rank under environmental protection performance.

\begin{tabular}{lrrr}
\hline $\begin{array}{l}\text { Process } \\
\text { no. }\end{array}$ & Preference index & Rank & $\begin{array}{r}\text { Degree of } \\
\text { belief that } \\
\text { business } \\
\text { process can } \\
\text { be the best }\end{array}$ \\
\hline$p=1$ & $(0.065,0.172,0.5)$ & 3 & 0.715 \\
$p=2$ & $(0.111,0.327,0.915)$ & 1 & 1 \\
$p=3$ & $(0.099,0.298,0.801)$ & 2 & 0.959 \\
$p=4$ & $(0.031,0.083,0.248)$ & 5 & 0.359 \\
$p=5$ & $(0.041,0.118,0.339)$ & 4 & 0.522 \\
\hline
\end{tabular}

The overall preference index of each business process was calculated by using this procedure. The rank of business processes with respect to all identified evaluation criteria and their weights and the degree of belief that a business process can be placed at first place in the rank were calculated and presented in Table 7.

\section{Discussion}

According to the final score, business process $p=2$ is preferred because it has the highest priority. According to the calculated degree of belief, it may be assumed that all identified processes are significant for the seaport and, at the same time, it can be suggested that the management team has defined an adequate reference model for an organization. In the last place in the rank is business process $p=4$. In the treated seaport, occupational health and environmental protection based on the OHSAS 18001 standard has been introduced recently. Some activities related to occupational health and environmental protection are delegated to employees that have not been part of the management team. From this fact, it can be concluded that the management team has not given a full commitment to the new demands and does not have enough knowledge; therefore, the assessment was obtained through previous experiences.
Table 6. Preference indices of business processes and their rank under safety performance.

\begin{tabular}{lrrr}
\hline $\begin{array}{l}\text { Process } \\
\text { no. }\end{array}$ & Preference index & Rank & $\begin{array}{r}\text { Degree of } \\
\text { belief that } \\
\text { business } \\
\text { process can } \\
\text { be the best }\end{array}$ \\
\hline$p=1$ & $(0.087,0.166,0.447)$ & 4 & 0.721 \\
$p=2$ & $(0.106,0.298,0.68)$ & 1 & 1 \\
$p=3$ & $(0.072,0.181,0.494)$ & 3 & 0.768 \\
$p=4$ & $(0.049,0.129,0.328)$ & 5 & 0.568 \\
$p=5$ & $(0.089,0.225,0.578)$ & 2 & 0.866 \\
\hline
\end{tabular}

Table 7. The overall preference index.

\begin{tabular}{lrrr}
\hline $\begin{array}{l}\text { Process } \\
\text { no. }\end{array}$ & $\begin{array}{r}\text { The overall preference } \\
\text { index }\end{array}$ & Rank & $\begin{array}{r}\text { Degree of } \\
\text { belief that } \\
\text { business } \\
\text { process can } \\
\text { be the best }\end{array}$ \\
\hline$p=1$ & $(0.065,0.231,0.9)$ & 2 & 0.956 \\
$p=2$ & $(0.066,0.269,1)$ & 1 & 1 \\
$p=3$ & $(0.067,0.175,0.697)$ & 4 & 0.869 \\
$p=4$ & $(0.028,0.107,0.409)$ & 5 & 0.677 \\
$p=5$ & $(0.055,0.215,1.686)$ & 3 & 0.918 \\
\hline
\end{tabular}

In the course of determining the appropriate actions for performance enhancement within each identified business process, it is necessary to present the sensitivity of each business process with respect to the KPIs and the main performances (Figs. 2 and 3).

Business process $p=1$ is the most sensitive with respect to quality performance. Since customers represent the end users of seaport services, a low level of quality of the treated business process will decrease profits. KPIs that generate the highest impact within this performance are Q2 and Q3. Management initiatives which could lead to the enhancement of the denoted KPIs are application quality methods (for example, quality function deployment, DefineMeasure-Analyse-Improve-and-Control, and cost-benefit analyses).

Business process $p=2$ is the most sensitive with respect to environmental protection. In relation to the conducted activities during this process's realization (maintenance of vessels, port transportation, cleaning, garbage and hazardous substance disposal, etc.), the quality of air and water could be decreased, and the generation of noise and leaking of hazardous substances could be increased. It may be concluded that all KPIs are almost equally important. Management initiatives that should lead to KPI values' enhancement should cover activities of the definition of procedures that are based on international standards and directives. Other ac- 


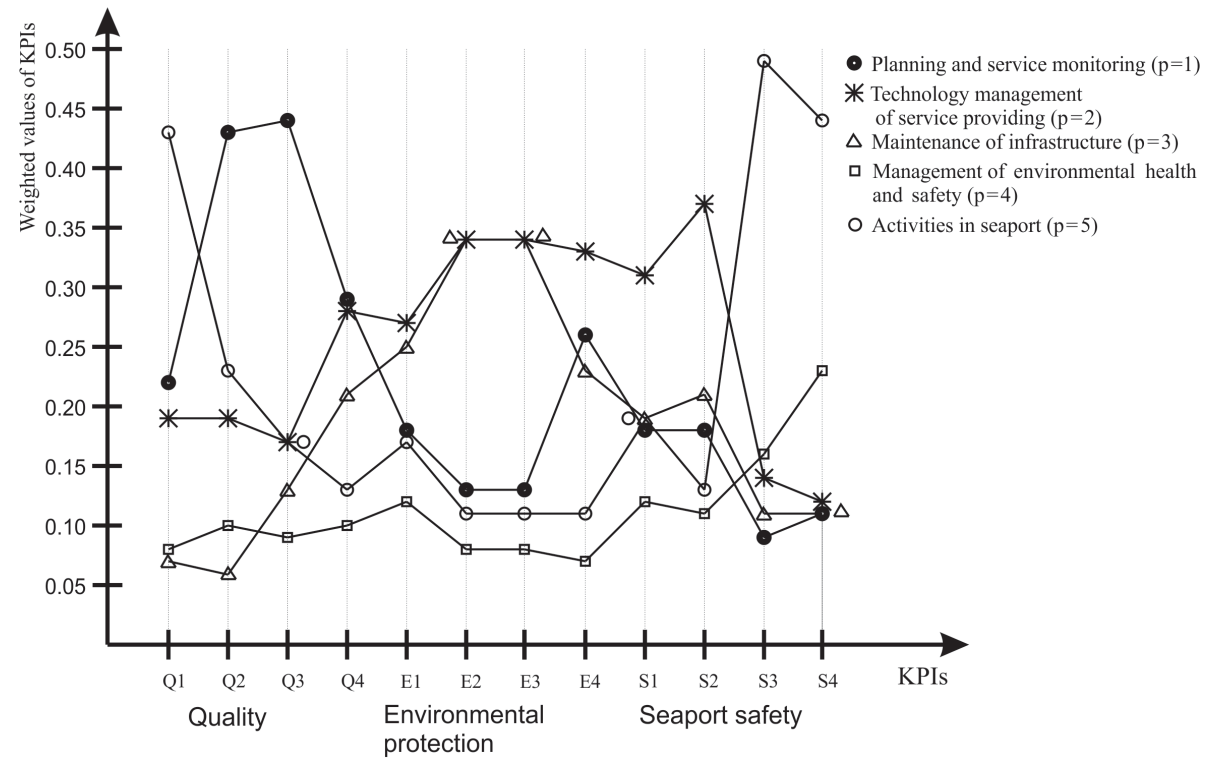

Figure 2. Sensitivity of each business process with respect to the KPIs.

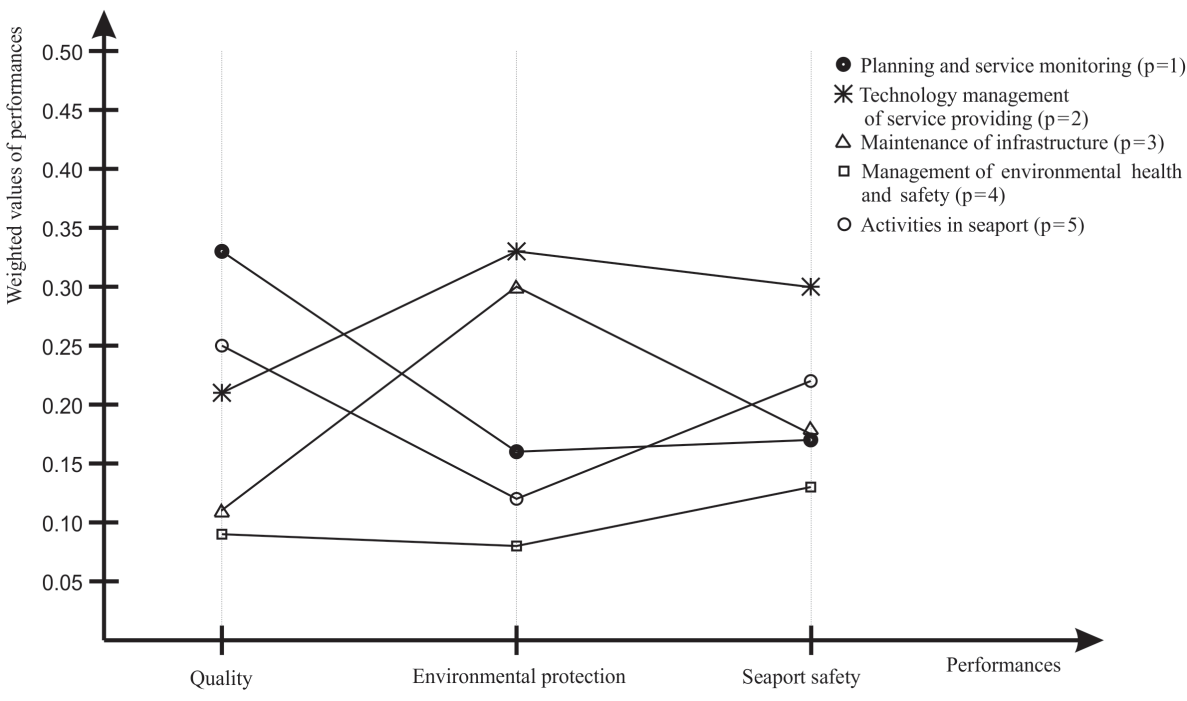

Figure 3. Sensitivity of each business process with respect to the performances.

tivities could be oriented to the training of employees. It is worth mentioning that business process $p=2$ is very sensitive to safety performance of the seaport. In that manner, KPI S2 has greatest impact on this performance.

Business process $p=3$ is the most sensitive in terms of environmental protection performance. Endangering the environment occurs during the implementation of maintenance dock activities and cranes, as well as other transport manipulating systems, warehouses, roads, etc. The most significant KPIs in the scope of this analysis are E2 and E3. The management initiatives that should lead to the KPI values' enhancement correspond to process $p=2$.
From the data in Fig. 2 and Tables 4-6, it can be concluded that the business process $p=4$ has an almost equal impact on all three treated performances. Enhancement of this business process can be achieved by applying different procedures, which should lead to the increase of KPI values' emphasizing of safety performance. These procedures should be in compliance with international standards and directives.

When business process $p=5$ is analysed, quality performance has the most significant impact in terms of sensitivity. Most of the activities generated by this process are customer oriented; therefore, low performances in this process could lead to a decrease in competitiveness and a bad image of the port. Enhancement of this process with respect to qual- 
ity performance may be achieved by applying the measures for enhancement of KPI Q2.

\section{Research implications}

By comparing papers which propose a model for evaluating business processes under uncertainties, certain differences could be noted, which are further described. This analysis, at the same time, shows the advantages of the proposed model.

In this paper, it is assumed that determination of the relative importance of the performance of business processes and the relative preference of KPIs of performances and priority of business processes are more reliable when obtained using pairwise comparisons than when they are directly obtained. This is because it is easier to make a comparison between two criteria than make to an overall weight assignment. The fuzzy pairwise comparison matrices of the relative importance of performances, their KPIs and preference of business processes were constructed. The weights vectors of performances and of KPIs under the performance and preferences vector of business processes for each KPI are calculated by using the method developed in Wu et al. (2004). This can be denoted as the main difference between this paper and others (Tadic et al., 2013; Pak et al., 2015; Kaya and Kahraman, 2011; Hsu, 2012).

The overall index of the preferences for each business process is described by TFNs. According to fuzzy algebra rules, values of the overall index of a preference are not TFNs, but it is possible to express approximated values of fuzzy operations as TFNs (Kwong and Bai, 2003). Therefore, according to the overall index of a preference, the ranking order of all business processes can be determined and the most important one from among a set of treated business processes can be selected. The degree of belief that any business process can be the business process associated with the highest value of the overall index of a preference can be determined. The priority of management initiatives that should lead to the enhancement of business processes should be based on the rank of business processes and the calculated degrees of belief. The introduced modifications in determining the priority of management measures represents the main difference and, at the same time, the advantage of the proposed model compared to the proposed FAHP methods which can be seen in the literature.

\section{Conclusion and future work}

Seaport management practices show that the evaluation and enhancement of business processes represent the most relevant issues for competitiveness and sustainability. The definition of an enhancement strategy should be based on the rank of the business processes. The main performances and their KPIs are determined in compliance with the process approach and ISO 20000-1:2000. A large number of decision variables demonstrating the complexities are involved in the ranking of business processes. It is assumed that the application of analytic methods in determining the rank of business processes is better than applying intuitive decision-making methods. It may be suggested that each solution obtained in an exact way is less encumbered by the subjective views of decision makers, which could make it more accurate.

A fuzzy AHP has been proposed. Uncertainties in the relative importance of each pair of performances and their KPIs and the preference of business processes with respect to each identified KPI are described by predefined linguistic expressions which are modelled by using the fuzzy sets theory. The fuzzy approach is easy to understand, flexible and tolerant to imprecise data. These linguistic expressions are modelled by TFNs.

The evaluation of the relative importance of business process performances and their KPIs is based on knowledge, the experience of the seaport decision makers, the needs of local government and other stakeholders. Applying fuzzy group decision-making in determining these decision variables can be considered as one of the contributions of this paper. The main contribution of this paper may be seen as an application of the proposed FAHP with the goal of obtaining the fuzzy rank of business processes and the degree of belief that a business process can be placed in first place. With respect to the fuzzy rank and degrees of belief, it is possible to rationalize the expenditure of time, money and other resources. Also, a good scheduling of management initiatives' orders could increase the efficiency of the enhancement strategy. This can be considered as the main contribution of the proposed FAHP, which was tested with real-life data; the obtained results were presented.

The main advantages of the proposed FAHP are related to the fact that it does not involve cumbersome mathematical operations, and it could be easily employed within seaports which operate in an uncertain environment. The proposed FAHP can be easily extended to the analysis of other management decision problems in different research areas. The general limitation of the model is the need for well-structured business processes and the comprehensible definition of their performances.

Finally, it is clear that further research could cover a more detailed decomposition of business processes, an increased number of performances and their KPIs, and connection of the business processes of the treated seaport with business processes of other seaports in similar regions.

\section{Data availability}

The setting of the problems and calculations are given in the Appendix. Additional explanations regarding the research in this paper may be obtained upon request by writing to the authors. 


\section{Appendix A: The obtained results}

For the purpose of calculation, the five linguistic expressions are proposed and modelled by TFNs as follows:

- very low importance/preferency is $\mathrm{VL}=(1,1,2)$;

- low importance/preferency is $L=(1,2,3)$;

- moderate importance/preferency is $M=(2,3,4)$;

- high importance/preferency is $H=(3,4,5)$; and

- very high importance/preferency is $\mathrm{VH}=(4,5,5)$.

The domains of fuzzy numbers can be defined on different scales (Ishizaka and Labib, 2009). In this paper, the domains of presented TFNs are defined by intervals [1-5].

The fuzzy pairwise matrix of dimensions $3 \times 3$ is assigned to the relative importance of considered performances.

The fuzzy matrices of dimensions $4 \times 4$ are assigned to the relative importance of KPIs under each performance.

In a similar way, the fuzzy pairwise comparison matrices of dimensions $5 \times 5$ are assigned to the preferences of business processes.

The elements of constructed fuzzy pairwise matrices are defuzzified and, after that, the consistency of fuzzy pairwise matrices is determined. This is determined by comparison with Torfi et al. (2010). The elements on the main diagonal are stated as one. This crisp value, according to the fuzzy sets theory, may be presented by TFN $(1,1,1)$.

The fuzzy pairwise comparison matrix of the relative importance of performances is presented by

$\left[\begin{array}{ccc}1 & M, H,(1,1,1), L & 1 / L, 1 / \mathrm{VL}, 1 / L,(1,1,1) \\ 1 / M, 1 / H,(1,1,1), 1 / L & 1 & 1 / M, 1 / H,(1,1,1), 1 / \mathrm{VL} \\ L,(1,1,1), L,(1,1,1) & M, H,(1,1,1), \mathrm{VL} & 1\end{array}\right]_{3 \times 3}$.

The application of FOWA is illustrated by the following example. The aggregated relative importance of quality performance $(k=1)$ over environmental protection performance $(k=2)$ can be calculated as

$$
\begin{aligned}
\widetilde{W}_{12} & =0.4 \cdot(2,3,4)+0.3 \cdot(3,4,5)+0.2 \cdot(1,1,1) \\
& +0.1 \cdot(1,2,3)=(2,2.8,3.6) .
\end{aligned}
$$

The fuzzy pairwise comparison matrix of the aggregated relative importance of performances is

$$
\begin{aligned}
& {\left[\begin{array}{ccc}
(0.28,0.36,0.5) & (2,2.8,3.6) & (0.45,0.7,1) \\
(1,1.43,2.22) & (1.72,1.96,2.44) & (0.41,0.51,0.58) \\
\text { C.I. }=0.048 & 1
\end{array}\right]_{3 \times 3},} \\
&
\end{aligned}
$$

The procedure for calculating quality weight is presented as follows:

$\alpha_{1}=\left[\prod_{k=1}^{3} 1 \cdot 2 \cdot 0.3\right]^{1 / 3}=0.89$

$$
\begin{aligned}
& \beta_{1}=\left[\prod_{k=1}^{3} 1 \cdot 2.8 \cdot 0.7\right]^{1 / 3}=1.25 \\
& \text { and } \chi_{1}=\left[\prod_{k=1}^{3} 1 \cdot 3.6 \cdot 1\right]^{1 / 3}=1.53 .
\end{aligned}
$$

Then,

$\alpha=\sum_{k=1}^{K} \alpha_{k}=2.65, \beta=\sum_{k=1}^{K} \beta_{k}=3.22$

and $\chi=\sum_{k=1}^{K} \chi_{k},=3.95$.

The weight of quality performance $(k=1)$ is calculated in compliance with Eqs. (2) and (3):

$$
\begin{aligned}
\widetilde{w}_{1} & =\left(0.89 \cdot 3.95^{-1}, 1.25 \cdot 3.22^{-1}, 1.53 \cdot 2.65^{-1}\right) \\
& =(0.24,0.39,0.58) .
\end{aligned}
$$

Similarly, the weights of the rest of the performances are calculated:

$\widetilde{w}_{2}=(0.12,0.17,0.25)$ and $\widetilde{w}_{3}=(0.30,0.44,0.66)$.

The fuzzy pairwise comparison matrix of the KPIs under quality performance is

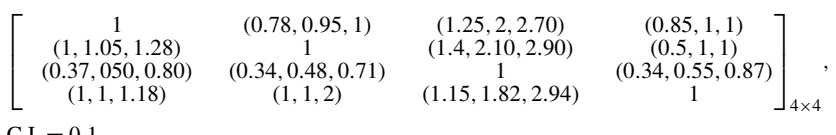

C.I. $=0.1$.

By using the procedure developed in $\mathrm{Wu}$ et al. (2004), the weights of the sub-criteria under quality performance are

$\widetilde{v}_{1}^{1}=(0.19,0.28,0.38), \widetilde{v}_{2}^{1}=(0.19,0.29,0.41)$,

$\widetilde{v}_{3}^{1}=(0.09,0.14,0.25)$ and $\widetilde{v}_{4}^{1}=(0.21,0.28,0.41)$.

The fuzzy pairwise comparison matrix of the KPIs under environmental protection performance is

$\left[\begin{array}{cccc}1 & (0.22,0.25,0.40) & (0.31,0.48,0.80) & (1,1,1.30) \\ (2.50,3.57,4.55) & 1 & (1.40,2.10,2.90) & (0.50,1,1) \\ (1.25,2.08,3.23) & (0.34,0.48,0.71) & 1 & (0.34,0.55,0.85) \\ (0.87,1,1) & (1,1,2) & (1.18,1.82,2.94) & 1\end{array}\right]_{4 \times 4}$

C.I. $=0.91$

The weights of KPIs under the environmental protection performance are

$\widetilde{v}_{1}^{2}=(0.09,0.14,0.25), \widetilde{v}_{2}^{2}=(0.21,0.39,0.59)$,

$\widetilde{v}_{3}^{2}=(0.11,0.20,0.36)$ and $\widetilde{v}_{4}^{2}=(0.18,0.27,0.48)$.

The fuzzy pairwise comparison matrix of the KPIs under the safety criterion is

$\left[\begin{array}{cccc}1 & (0.67,0.90,1) & (2.30,3.30,4.30) & (3.50,4.50,5) \\ (1,1.11,1.49) & 1 & (2.30,3.30,4.30) & (3.80,4.80,4.90) \\ (0.23,0.3,0.43) & (0.23,0.3,0.43) & 1 & (1.50,2.50,3.50) \\ (0.20,0.22,0.29) & (0.20,0.21,0.26) & (0.29,040,0.67) & 1\end{array}\right]_{4 \times 4}$, 
C.I. $=0.016$.

The weights of KPIs under the safety performance are

$\widetilde{v}_{1}^{3}=(0.26,0.38,0.52), \widetilde{v}_{2}^{3}=(0.29,0.41,0.58)$,

$\widetilde{v}_{3}^{3}=(0.09,0.14,0.22)$ and $\widetilde{v}_{4}^{3}=(0.06,0.07,0.11)$.

Similarly, the fuzzy pairwise comparison matrices of the business processes' preference are presented.

\section{A1 Quality performance}

(Q1) Quality of the seaport services

$\left[\begin{array}{ccccc}1 & L & L & H & 1 / M \\ 1 / L & 1 & M & M & 1 / L \\ 1 / L & 1 / M & 1 & 1 / L & 1 / \mathrm{VH} \\ 1 / H & 1 / M & L & 1 & 1 / \mathrm{VH} \\ M & L & \mathrm{VH} & \mathrm{VH} & 1\end{array}\right]_{5 \times 5} \quad$, C.I. $=0.058$.

$\tilde{p}_{11}^{1}=(0.12,0.22,0.41), \tilde{p}_{21}^{1}=(0.11,0.19,0.38)$,

$\tilde{p}_{31}^{1}=(0.05,0.07,0.14), \tilde{p}_{41}^{1}=(0.05,0.08,0.14)$

and $\tilde{p}_{51}^{1}=(0.25,0.43,0.68)$.

(Q2) Average number of customers

$$
\begin{aligned}
& {\left[\begin{array}{ccccc}
1 & \mathrm{VH} & H & M & H \\
1 / \mathrm{VH} & 1 & \mathrm{VL} & \mathrm{VL} & 1 / H \\
1 / H & 1 / \mathrm{VL} & 1 & 1 / H & 1 / \mathrm{VH} \\
1 / M & 1 / \mathrm{VL} & H & 1 & 1 / L \\
1 / H & H & \mathrm{VH} & L & 1
\end{array}\right]_{5 \times 5}, \text { C.I. }=0.085 .} \\
& \tilde{p}_{12}^{1}=(0.28,0.43,0.62), \widetilde{p}_{22}^{1}=(0.14,0.19,0.29) \\
& \widetilde{p}_{32}^{1}=(0.04,0.06,0.09), \\
& \text { and } \widetilde{p}_{52}^{1}=(0.14,0.23,0.34)
\end{aligned}
$$

(Q3) Average number of vessels in the queue

$$
\begin{aligned}
& {\left[\begin{array}{ccccc}
1 & \mathrm{VH} & H & L & M \\
1 / \mathrm{VH} & 1 & L & L & \mathrm{VL} \\
1 / H & 1 / L & 1 & L & \mathrm{VL} \\
1 / L & 1 / L & 1 / L & 1 & 1 / M \\
1 / M & 1 / \mathrm{VL} & 1 / \mathrm{VL} & M & 1
\end{array}\right]_{5 \times 5}, \text { C.I. }=0.093 .} \\
& \tilde{p}_{1}^{1}=(0.25,0.44,0.72), \tilde{p}_{23}^{1}=(0.1,0.17,0.3), \\
& \tilde{p}_{33}^{1}=(0.08,0.13,0.26), \tilde{p}_{43}^{1}=(0.06,0.09,0.2) \\
& \text { and } \tilde{p}_{53}^{1}=(0.12,0.17,0.27)
\end{aligned}
$$

(Q4) Pilotage and operation of the vessel

$$
\left[\begin{array}{ccccc}
1 & L & L & \mathrm{VL} & 1 / M \\
1 / L & 1 & M & L & 1 / M \\
1 / L & 1 / M & 1 & M & 1 / H \\
1 / \mathrm{VL} & 1 / L & 1 / M & 1 & 1 / \mathrm{VH} \\
M & M & H & \mathrm{VH} & 1
\end{array}\right]_{5 \times 5} \quad \text {, C.I. }=0.1 .
$$

$\tilde{p}_{14}^{1}=(0.15,0.29,0.58), \tilde{p}_{24}^{1}=(0.14,0.28,0.54)$,

$\tilde{p}_{34}^{1}=(0.09,0.21,0.34), \widetilde{p}_{44}^{1}=(0.06,0.1,0.14)$

and $\tilde{p}_{54}^{1}=(0.07,0.13,0.26)$.

\section{A2 Environmental protection}

(E1) Quality of air

$$
\begin{aligned}
& {\left[\begin{array}{ccccc}
1 & 1 / L & 1 / L & M & \mathrm{VL} \\
L & 1 & \mathrm{VL} & M & \mathrm{VL} \\
L & 1 / \mathrm{VL} & 1 & L & \mathrm{VL} \\
1 / M & 1 / M & 1 / L & 1 & L \\
1 / \mathrm{VL} & 1 / \mathrm{VL} & 1 / \mathrm{VL} & 1 / L & 1
\end{array}\right]_{5 \times 5}, \text { C.I. }=0.1 .} \\
& \widetilde{p}_{11}^{2}=(0.11,0.18,0.32), \widetilde{p}_{21}^{2}=(0.17,0.27,0.40), \\
& \widetilde{p}_{31}^{2}=(0.15,0.25,0.44), \widetilde{p}_{41}^{2}=(0.07,0.12,0.23) \\
& \text { and } \widetilde{p}_{51}^{2}=(0.10,0.17,0.25) .
\end{aligned}
$$

(E2) Water quality and (E3) noise

$$
\begin{aligned}
& {\left[\begin{array}{ccccc}
1 & 1 / M & 1 / M & H & \mathrm{VL} \\
M & 1 & \mathrm{VL} & H & H \\
M & 1 / \mathrm{VL} & 1 & H & H \\
1 / H & 1 / H & 1 / H & 1 & L \\
1 / \mathrm{VL} & 1 / H & 1 / L & 1 / L & 1
\end{array}\right]_{5 \times 5} \quad, \text { C.I. }=0.77 .} \\
& \widetilde{p}_{12}^{2}=\widetilde{p}_{13}^{2}=(0.09,0.13,0.24), \\
& \widetilde{p}_{22}^{2}=\widetilde{p}_{23}^{2}=(0.22,0.34,0.59), \\
& \widetilde{p}_{32}^{2}=\widetilde{p}_{33}^{2}=(0.19,0.34,0.51), \\
& \widetilde{p}_{42}^{2}=\widetilde{p}_{43}^{2}=(0.05,0.08,0.14) \\
& \text { and } \widetilde{p}_{52}^{2}=\widetilde{p}_{53}^{2}=(0.06,0.11,0.18) .
\end{aligned}
$$

(E4) Hazardous substances

$$
\begin{aligned}
& {\left[\begin{array}{ccccc}
1 & 1 / \mathrm{VL} & 1 / \mathrm{VL} & \mathrm{VH} & M \\
\mathrm{VL} & 1 & \mathrm{VL} & H & M \\
\mathrm{VL} & 1 / \mathrm{VL} & 1 & \mathrm{VH} & L \\
1 / \mathrm{VH} & 1 / H & 1 / \mathrm{VH} & 1 & 1 / M \\
1 / M & 1 / M & 1 / L & M & 1
\end{array}\right]_{5 \times 5} \quad, \text { C.I. }=0.016 .} \\
& \widetilde{p}_{14}^{2}=(0.15,0.26,0.4), \widetilde{p}_{24}^{2}=(0.18,0.33,0.53), \\
& \widetilde{p}_{34}^{2}=(0.14,0.23,0.43), \widetilde{p}_{44}^{2}=(0.05,0.07,0.12) \\
& \text { and } \widetilde{p}_{54}^{2}=(0.07,0.11,0.22)
\end{aligned}
$$

\section{A3 Seaport safety}

(S1) Vessel safety

$$
\left[\begin{array}{ccccc}
1 & \mathrm{VL} & 1 / \mathrm{VL} & \mathrm{VL} & \mathrm{VL} \\
1 / \mathrm{VL} & 1 & L & M & L \\
\mathrm{VL} & 1 / L & 1 & L & \mathrm{VL} \\
1 / \mathrm{VL} & 1 / M & 1 / L & 1 & 1 / L \\
1 / \mathrm{VL} & 1 / L & \mathrm{VL} & L & 1
\end{array}\right]_{5 \times 5} \quad, \text { C.I. }=0.03 .
$$


$\tilde{p}_{11}^{3}=(0.12,0.19,0.35), \tilde{p}_{21}^{3}=(0.14,0.31,0.54)$,

$\widetilde{p}_{31}^{3}=(0.11,0.19,0.43), \widetilde{p}_{41}^{3}=(0.06,0.12,0.23)$

and $\widetilde{p}_{51}^{3}=(0.09,0.19,0.38)$.

(S2) Traffic volume
(S4) Other safety factors

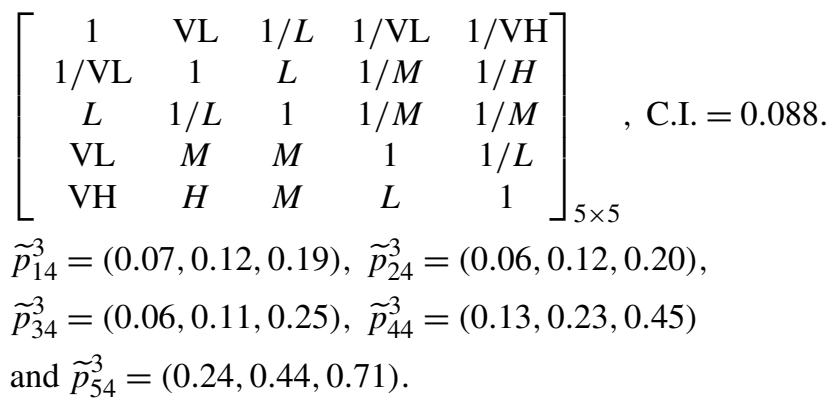

$\widetilde{p}_{12}^{3}=(0.14,0.18,0.36), \widetilde{p}_{22}^{3}=(0.2,0.37,0.56)$,

$\widetilde{p}_{32}^{3}=(0.12,0.21,0.35), \widetilde{p}_{42}^{3}=(0.06,0.11,0.16)$

and $\widetilde{p}_{52}^{3}=(0.08,0.13,0.24)$.

(S3) Weather, sea, and channel conditions

$\left[\begin{array}{ccccc}1 & \mathrm{VL} & 1 / L & 1 / L & 1 / \mathrm{VH} \\ 1 / \mathrm{VL} & 1 & \mathrm{VL} & L & 1 / H \\ L & 1 / \mathrm{VL} & 1 & 1 / M & 1 / H \\ L & 1 / L & M & 1 & 1 / M \\ \mathrm{VH} & H & H & M & 1\end{array}\right]_{5 \times 5} \quad$, C.I. $=0.084$.

$\tilde{p}_{13}^{3}=(0.06,0.09,0.16), \tilde{p}_{23}^{3}=(0.09,0.14,0.24)$,

$\tilde{p}_{33}^{3}=(0.06,0.11,0.18), \tilde{p}_{43}^{3}=(0.09,0.16,0.30)$

and $\widetilde{p}_{53}^{3}=(0.31,0.49,0.74)$. 
Competing interests. The authors declare that they have no conflict of interest.

Acknowledgements. This paper is dedicated to the memory of the late Zoran Kljajic, the scientist of the Institute of Marine Biology in Kotor, Montenegro.

Edited by: R. Archetti

Reviewed by: one anonymous referee

\section{References}

Aleksic, A., Stefanovic, M., Arsovski, S., and Tadic, D.: An assessment of organizational resilience potential in SMEs of the process industry, a fuzzy approach, J. Loss Prevent Proc., 26, 12381245, doi:10.1016/j.jlp.2013.06.004, 2013.

Ali, M. C.: Exploring the potential of integration quality assessment system in construction (qlassic) with ISO 9001 quality management system (QMS), Int. J. Qual. Res., 8, 73-86, 2013.

Ali, M. C.: Exploring the potential of integration quality assessment system in construction (qlassic) with ISO 9001 quality management system (QMS), Int. J. Qual. Res., 8, 73-86, 2014.

Arsovski, S.: Integrated Management Systems, Kragujevac, Serbia: Faculty of Engineering, Kragujevac, Serbia: Faculty of engineering, University of Kragujevac, Kragujevac, Serbia, 2013.

Balmat, J. F., Lafont, F., Maifret, R., and Pessel, N.: MAritime RISk Assessment (MARISA), a fuzzy approach to define an individual ship risk factor, Ocean Eng., 36, 1278-1286, doi:10.1016/j.oceaneng.2009.07.003, 2009.

Bass, M. S. and Kwakernaak, H.: Rating and Ranking of Multipleaspect Alternatives using Fuzzy sets, Automatica, 3, 47-58, doi:10.1016/0005-1098(77)90008-5, 1977.

Chan, F. T. S. and, Kumar, N.: Global supplier development considering risk factors using fuzzy extended AHPbased approach, Omega Int. J. Manage. S., 35, 417-431, doi:10.1016/j.omega.2005.08.004, 2007.

Chang, D. Y.: Applications of the extent analysis method on fuzzy AHP, Eur. J. Oper. Res., 95, 649-655, doi:10.1016/03772217(95)00300-2, 1996.

Dubois, D. and Prade, H.: Decision-making under fuzziness, in: Advances in Fuzzy Set Theory and Applications, edited by: Gupta, M. M., Pagade, R. K., and Yager, P. R., North-Holland, Amsterdam, the Netherlands, 279-302, 1979.

Hsu, W. K.: Port's service attributes for ship navigation safety, Safety Sci., 50, 244-252, 2012.

Ishizaka, A. and Labib, A.: Analytic hierarchy process and expert choice: Benefits and limitations, OR Insight, 22, 201-220, 2009.

John, A., Paraskevadakis, D., Bury, A., Yang, Z., Riahi, R., and Wang, J.: An integrated fuzzy risk assessment for seaport operations, Safety Sci., 68, 180-194, doi:10.1016/j.ssci.2014.04.001, 2014.

Kaya, T, and Kahraman, C.: Multicriteria decision making in energy planning using a modified fuzzy TOPSIS methodology, Expert Syst Appl, 38, 6577-6585, doi:10.1016/j.eswa.2010.11.081, 2011.

Klir, G. J. and Folger, T.: Fuzzy Sets, Uncertainty, and Information, Prentice Hall, Upper Saddle River, NJ, USA, 1988.
Kuo, R. J., Chi, S. C., and Kao, S. S.: A decision support system for locating convenience store through fuzzy AHP, Comput. Ind. Eng., 37, 323-326, doi:10.1016/S0360-8352(99)00084-4, 1999.

Kwong, C. K. and Bai, H.: Determining the importance weights for the customer requirements in QFD using a fuzzy AHP with an extent analysis approach, IEEE Trans., 35, 619-625, doi:10.1080/07408170304355, 2003.

Medison, D.: Process Mapping, Process Improvement and Process Management, Paton Professional, California, 2005.

Merigo, J. M. and Casanovas, M.: Using fuzzy numbers in heavy aggregation operators, Int. J. Inform. Technol., 4, 267-272, 2008.

Oakland, J.: Oakland on quality management, Elsevier ButterworthHeinemann, Oxford, Burlington, 2004.

Pak, J. Y., Yeo, G. T., Oh, S. W., and Yang, Z.: Port safety evaluation from a captain's perspective: The Korean experience, Safety Sci., 72, 172-181, doi:10.1016/j.ssci.2014.09.007, 2015.

Poli, M., Petroni, D., Pardini, S., Salvadori, A. P., and Menichetti, L.: Implementation of a quality assurance system according to GMP and ISO 9001:2008 standard for radiopharmaceutical production in a public research centre, Accred. Qual. Assur., 17, 341-348, doi:10.1007/s00769-012-0877-3, 2012.

Saaty, T. L.: Decision making with the analytic hierarchy process, Int. J. Serv. Sci., 1, 83-98, 2008.

Sedani, C. M. and Lakhe, R. R.: ISO 9000 QMS \& TQM performance measure: Analysis of pilot study, J. Indian Manage. Strat., 16, 59-64, 2011.

Shafieezadeh, A. and Burden, L.: Scenario-based resilience assessment framework for critical infrastructure systems: Case study for seismic resilience of seaports, Reliab. Eng. Syst. Safe., 132, 207-219, doi:10.1016/j.ress.2014.07.021, 2014.

Spiegel, T. and Caulliraux, H. M.: Developing an organizational reference model by selecting and integrating multiple references, J. Manage. Res., 4, 1-23, doi:10.5296/jmr.v4i1.1059, 2012.

Tadic, D., Gumus, A. T., Arsovski, S., Aleksic, A., and Stefanovic, M.: An evaluation of Quality Goals by Using Fuzzy AHP and Fuzzy TOPSIS Methodology, J. Intel. Fuzzy Syst., 25, 547-556, doi:10.3233/IFS-120659, 2013.

Tadic, D., Arsovski, S., Aleksic, A., Stefanovic, M., and Nestic, S.: A Fuzzy Evaluation of Projects for Business Processes' Quality Improvement, in: Intelligent Techniques in Engineering Management, Intelligent Systems Reference Library, edited by: Kahraman, C. and Onar, S. Ç., Springer International Publishing, Switzerland, 559-579, 2015.

Torfi, F., Farahani, R. Z., and Rezapour, S.: Fuzzy AHP to determine the relative weights of evaluation criteria and Fuzzy TOPSIS to rank the alternatives, Appl. Soft Comput., 10, 520-528, doi:10.1016/j.asoc.2009.08.021, 2010.

Trbojevic, V. and Carr, B.: Risk based methodology for safety improvements in ports, J. Hazard. Mater., 71, 467-480, doi:10.1016/S0304-3894(99)00094-1, 2000.

Wang, Y. M., Luo, Y., and Hua, Z.: On the extent analysis method for fuzzy AHP and its applications, Eur. J. Oper. Res., 186, 735747, doi:10.1016/j.ejor.2007.01.050, 2008.

Woo, S. H., Pettit, S. J., Kwak, D. W., and Beresford, A. K. C.: Seaport research: A structured literature review on methodological issues since the 1980s, Transp, Res. A, 45, 667-685, doi:10.1016/j.tra.2011.04.014, 2011. 
Wu, X. Q., Pu, F., Shao, S. H., and Fang, J. N.: Trapezoidal fuzzy AHP for the comprehensive evaluation of highway network programming schemes in Yangtze River Delta, in: Proceedings of the 5th World Congress On Intelligent Control and Automation, 15-19 June 2004, Hangzhou, China, 5232-5236, 2004.
Yaqiong, L., Ka Man, L., and Zhang, W.: Fuzzy theory applied in quality management of distributed manufacturing system: A literature review and classification, Eng. Appl. Artif. Intel., 24, 266-277, doi:10.1016/j.engappai.2010.10.008, 2011.

Zimmermann, H. J.: Fuzzy Set Theory and its Applications, Kluwer Nijhoff Publishing, Boston, USA, 2001. 